\title{
Hereditary Angioedema with and Without C1-Inhibitor Deficiency in Postmenopausal Women
}

\author{
Aurore Billebeau ${ }^{1} \cdot$ Olivier Fain $^{2} \cdot$ David Launay $^{3} \cdot$ Isabelle Boccon-Gibod ${ }^{4} \cdot$ Laurence Bouillet $^{4} \cdot$ Delphine Gobert $^{2}$. \\ Geneviève Plu-Bureau ${ }^{1}$ • Anne Gompel ${ }^{1,5}$ (D) French National Reference Center for Hereditary Angioedema (CREAK)
}

\begin{abstract}
Purpose Most types of hereditary angioedema (HAE) are worsened by endogenous or exogenous estrogens. Conversely, androgens can improve HAE with abnormal C1-Inhibitor (C1-INH) by increasing C1-INH concentrations. Menopause is associated with an extinction of ovarian estrogenic and androgenic secretion. There is currently insufficient information on postmenopausal women with HAE. The objective of this study was to describe the activity of HAE in postmenopausal women. Methods This was a French retrospective, multicenter study in postmenopausal women with HAE with or without C1-INH deficiency/dysfunction. The patients were classified before and after menopause with a previously validated HAE disease severity score.

Results We included 65 women from 13 centers in France. The mean age was $62.7 \pm 9.2$ years, and the mean time between menopause and inclusion was $12.5 \pm 9.1$ years. HAE was associated with C1-INH deficiencyin $88 \%(n=57)$ of the patients, a mutation of factor 12 in $8 \%(n=5)$, a mutation in plasminogen gene in one, and unknown HAE for two. The HAE course was not different after menopause in $46.1 \%(n=30)$, improved in $38.5 \%(n=25)$, and worsened in $15.4 \%(n=10)$. Improvement was correlated with estrogen sensitivity of angioedema before menopause ( $p=0.06$ for improvement vs no effect or worsening). In addition, we observed that only ten women received treatment (transdermal or oral estradiol+ progestogen) for their menopause symptoms. Among them, only 3 experienced worsening of symptoms ( 2 on transdermal and 1 on oral estradiol).

Conclusion Following menopause, most women with HAE remain stable but some worsen. Improvement was mainly observed in patients with previous estrogen sensitivity. More research is required in menopausal women with HAE to better understand how to manage climacteric symptoms.
\end{abstract}

Keywords Hereditary angioedema $\cdot$ menopause $\cdot$ female $\cdot$ estrogen $\cdot$ androgen $\cdot$ aging

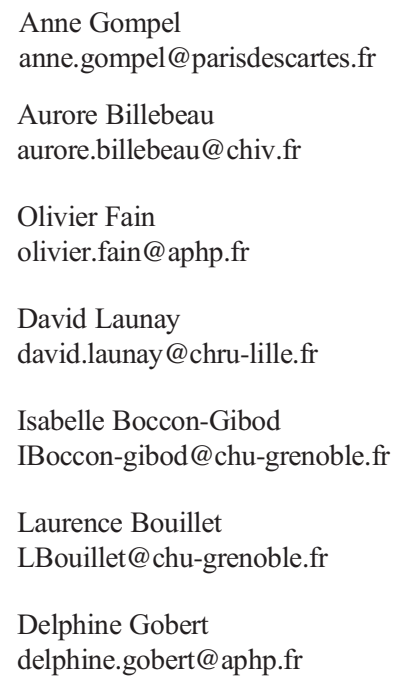

Geneviève Plu-Bureau

genevieve.plu-bureau@aphp.fr

1 AP-HP, HUPC, Unité de Gynécologie Endocrinienne, Centre de Référence sur les angiœedèmes à kinines (CRéAk), Hôpital Port Royal, Université de Paris, Paris, France

2 AP-HP, Médecine Interne, DHUi2B, Centre de Référence associé sur les angiœdèmes à kinines (CRéAk), Hôpital Saint-Antoine, Sorbonne Université, Paris, France

3 Inserm, CHU Lille, U995 - LIRIC - Lille Inflammation Research International Center, Centre de Référence sur les angiœdèmes à kinines (CRéAk), France Service de Médecine Interne, Université de Lille, F-59000 Lille, France

4 Unité Inserm 1036, Service de Médecine Interne, Centre de Référence sur les angiœdèmes à kinines (CRéAk), CHU de Grenoble Alpes, Université Grenoble Alpes, Grenoble, France

5 Université de Paris, 123 bd de Port Royal, 75014 Paris, France 


$\begin{array}{ll}\text { Abbreviations } & \\ \text { C1-INH } & \text { C1-Inhibitor } \\ \text { HAE } & \text { Hereditary angioedema } \\ \text { C 1 - I N H } & \text {-Hereditary angioedema with C1-Inhibitor de- } \\ \text { HAE } & \text { ficiency/dysfunction } \\ \text { n C 1 - I N H } & \text {-Hereditary angioedema with normal C1- } \\ \text { HAE } & \text { Inhibitor } \\ \text { pdC1-INH } & \text { Plasma-derived concentrate C1-Inhibitor } \\ \text { COC } & \text { Estroprogestin combined (oral) contraception } \\ \text { POP } & \text { Progestin-only pills } \\ \text { AGP } & \text { Antigonadotropic } \\ \text { MHT } & \text { Menopause hormone treatment } \\ \text { TTS-E2 } & \text { Transdermal estradiol } \\ \text { BMI } & \text { Body mass index } \\ \text { TA } & \text { Tranexamic acid }\end{array}$

\section{Introduction}

Hereditary angioedema (HAE) is a rare disease characterized by recurrent, self-resolving, and unpredictable episodes of subcutaneous and/or submucosal swellings affecting any area of the skin as well as the respiratory and gastrointestinal tracts. HAE can be classified into two subtypes: HAE with C1Inhibitor (C1-INH) deficiency (type I) or dysfunction (type II) (C1-INH-HAE) caused by mutations in the C1-INH coding gene, SERPING1, resulting in a quantitative and/or qualitative C1-INH deficiency; and normal C1-INH-HAE (nC1-INH-HAE) [1-3]. This latter type is associated with a mutation on the $F 12$ gene (Hageman factor) in about $30 \%$ of cases [2,4], and more rarely, a mutation in other genes like the plasminogen (PLG), angiopoietin 1 (ANG1), and kininogen 1 (KNG1) genes [4-10]. Among patients with nC1-INH-HAE some do not have any mutations so far identified and are called unknown C1-INH-HAE (UHAE) [4]. nC1-IHN-HAE could represent around a tenth of patients with HAE, but the proportion of mutations can vary from one population to another $[8,9]$.

Triggers of HAE include infection, mental stress, physical activity, local trauma, and fatigue [3, 11]. C1-INH-HAE and nC1-INH-HAE with F12 mutation (F12-HAE) are also influenced by fluctuations of the female hormones and can be worsened by estrogens [12-14] whereas the other subtypes of nC1-INH seem not to be, or are less, influenced by reproductive life. Nevertheless, we still lack information about these types of nC1-INH-HAE as they have only been described quite recently [5-7]. For the subtypes of HAE influenced by estrogens, the frequency of symptoms may vary according to fluctuations in estrogens: both endogenous (reproductive stage, puberty, menstruation, pregnancy) and exogenous [12-14]. Menopause combines both an extinction of ovarian estrogenic and androgenic secretion and is followed by progressive aging. Treatment with attenuated androgens is effective in patients with C1-INH-HAE $[2,15]$. Since estrogens may worsen and androgens improve the course of HAE, describing changes brought about by the menopause in women with HAE is an interesting area of research. A previous study, which included 44 menopausal women with C1INH-HAE, reported that menopause was associated with no modification in 55\%, an improvement in 13\%, and a worsening in $32 \%$ [13]. We set out to update this information in a larger series of patients including women with both C1-INH-HAE and nC1-INH-HAE. In addition, we evaluated the course of HAE after menopause according to the impact of the hormonal factors in the premenopausal clinical history of the women.

\section{Methods}

We conducted a multicenter, retrospective study between June 2016 and June 2017 of postmenopausal women with HAE from 13 sites of the National Angioedema Reference Center (CREAK). All postmenopausal patients with type I or II C1-INH-HAE, or nC1-INH-HAE with a F12 mutation, another known mutation or without a F12 mutation (U-HAE) but with a family history, were eligible for inclusion. Diagnosis was performed in a reference center according to the International Recommendations and based on measuring C1-INH concentration and function, $\mathrm{C} 4$ level, and genetic testing if the mutation was not known in the family or in the absence of family history $[1,2]$. Patients with idiopathic non-histaminergic angioedema were excluded. The age of menopause was determined by the referring physician or gynecologist. If this information was missing, menopause was defined as amenorrhea for $\geq 12$ months in women over $\geq 51$ years of age.

All consenting patients were contacted by telephone by a member of the study team $(\mathrm{AB})$ to answer an initial 20-min questionnaire, and in 61 (91\%) cases, a second 1-h interview was conducted to gather the information. Any missing or incomplete information was collected from the patients' medical charts including their history of HAE.

The following data were collected for all of the patients: clinical data, family history, frequency of HAE attacks, site of the attacks before and after menopause, age at onset and age at diagnosis, age at menopause, comorbidities including cardiovascular risk, cancer and auto-immune diseases, estrogen sensitivity (i.e., the influence of puberty, pregnancy, menstrual cycle, exogenous estrogens, progestins, and menopause hormonal treatment (MHT) on the attacks), and therapeutic management. The Menopause Rating Scale (MRS) was used to assess menopausal symptom severity [16]. This is a validated health-related quality of life questionnaire that consists of 11 items grouped into three categories: somatic, psychological, and urogenital. Each item is a menopausal symptom which is graded on a 5-point Likert 
scale from 0 to 4: a score of 0 denotes "no symptom," a score of 1 "mild," 2 "moderate," 3 "severe," and a maximum score of 4 "very severe." We calculated the total score by adding the sum-scores of the 11 items, and we considered menopause symptoms to be severe if the total score was 16 or more [17].

The previously described HAE disease severity score, published by Prior et al., was used to classify the severity of HAE in the patients [18]. This severity score was evaluated as an average over the 5 years preceding menopause and then over the 6-month period preceding inclusion in the study (i.e., the postmenopausal period). The patients were classified into one of four groups according to the severity of HAE: the Asymptomatic Group for women with no angioedema episodes and no long-term prophylactic treatment; the Mild Group for women with no life-threatening angioedema episodes, $\leq 6$ episodes/year and no long-term prophylactic treatment; the Moderate Group for women with no life-threatening angioedema episodes, $\leq 12$ episodes/year and long-term prophylactic treatment with either danazol or tranexamic acid (TA) but not pdCC1-INH, or $>6$ episodes/year without longterm prophylactic treatment; and the Severe Group for women with life-threatening angioedema episodes, and/or
$>12$ episodes/year with long-term prophylactic treatment with pdCC1-INH. An improvement was reported if the patient was classified into a less severe group, and a worsening if the patient was classified into a more severe group. A patient was considered to be stable if she stayed in the same group after menopause.

This study was approved by the Local Ethics Committee at Paris Descartes University (Ref CPPIDF1-2016-Février-DAP 08 ) and by the French National Information Science and Liberties Commission ( $\mathrm{N}^{\circ} 141934068$ v 0).

\section{Statistical Analysis}

Results are presented as mean \pm standard deviation (SD) or median [range] for quantitative data and percentages for qualitative data. Comparisons between two independent groups were performed using the chi-squared test for qualitative data, or Fischer's exact test depending on the conditions of application of the test. $P$ values $<0.05$ were considered to denote a significant difference. Logistic regression was used to determine predictive factors for HAE course at menopause. Multivariate analysis including hormone dependency, body
Table 1 Clinical characteristics and frequency of HAE attacks after menopause according to the subtype of HAE

\begin{tabular}{|c|c|c|c|c|}
\hline & \multirow{2}{*}{$\begin{array}{l}\text { HAE type I } \\
(n=57)\end{array}$} & \multicolumn{3}{|l|}{ nC1-INH-HAE } \\
\hline & & $\begin{array}{l}\text { F12 mutation } \\
(n=5)\end{array}$ & $\begin{array}{l}\text { PLG } \\
(n=1)\end{array}$ & $\begin{array}{l}\text { U-HAE } \\
(n=2)\end{array}$ \\
\hline \multicolumn{5}{|l|}{ Frequency of attacks } \\
\hline Never, $n(\%)$ & $16(28.1)$ & $3(60.0)$ & & $2(100.0)$ \\
\hline$\leq 3$ attacks in previous 6 months, $n(\%)$ & $21(36.8)$ & $0(0.0)$ & $1(100)$ & $0(0.0)$ \\
\hline $\begin{array}{l}\text { Between } 4 \text { and } 5 \text { attacks in previous } \\
\quad 6 \text { months, } n(\%)\end{array}$ & $2(3.5)$ & $0(0.0)$ & & $0(0.0)$ \\
\hline $\begin{array}{l}\text { Between } 6 \text { and } 12 \text { attacks in previous } \\
\quad 6 \text { months, } n(\%)\end{array}$ & $9(15.8)$ & $2(40.0)$ & & $0(0.0)$ \\
\hline$>12$ attacks in previous 6 months, $n(\%)$ & $9(15.8)$ & $0(0.0)$ & & $0(0.0)$ \\
\hline \multicolumn{5}{|l|}{ Localization of attacks } \\
\hline Larynx, $n(\%)$ & $4(7.0)$ & $0(0.0)$ & $1(100)$ & $0(0.0)$ \\
\hline Abdomen, $n(\%)$ & $39(68.4)$ & $0(0.0)$ & $0(100)$ & $1(50.0)$ \\
\hline Members, $n(\%)$ & $41(71.9)$ & $2(0.4)$ & $0(100)$ & $1(50.0)$ \\
\hline \multicolumn{5}{|l|}{ Long-term prophylactic treatment } \\
\hline None, $n(\%)$ & $19(33.3)$ & $3(60.0)$ & $1(100)$ & $2(100.0)$ \\
\hline Danazol, $n(\%)$ & $24(42.1)$ & $0(0.0)$ & & $0(0.0)$ \\
\hline Tranexamic acid, $n(\%)$ & $8(14.0)$ & $2(40.0)$ & & $0(0.0)$ \\
\hline pd C1-INH concentrate, $n(\%)$ & $6(10.6)$ & $0(0.0)$ & & $0(0.0)$ \\
\hline \multicolumn{5}{|l|}{ Severity score } \\
\hline Asymptomatic, $n(\%)$ & $5(8.8)$ & $3(60.0)$ & & $2(100.0)$ \\
\hline Mild, $n(\%)$ & $9(15.8)$ & $1(20.0)$ & $1(100)$ & $0(0.0)$ \\
\hline Moderate, $n(\%)$ & $28(49.2)$ & $1(20.0)$ & & $0(0.0)$ \\
\hline Severe, $n(\%)$ & $15(26.3)$ & $0(0.0)$ & & $0(0.0)$ \\
\hline
\end{tabular}

HAE type I hereditary angioedema with C1-Inhibitor deficiency, $n C 1-I N H$ HAE hereditary angioedema with normal C1-Inhibitor, PLG plasminogen, U-HAE HAE without known mutation 
mass index (BMI), time since menopause, menopausal symptom severity, and morbidities were performed to determine HAE progression after menopause. The statistical analysis was performed with the SAS software (SAS Institute Inc., Cary, NC, USA).

\section{Results}

Of the 65 patients included, $88 \%$ had type I C1-INH-HAE (HAE type I) $(n=57), 6.7 \%$ had nC1-INH-HAE and F12 mutation $(n=5$, mutation c. $983 \mathrm{C}>\mathrm{A}$ (p. Thr328Lys)), one patient had nC1-INH-HAE with a pathogenic variant in the $P L G$ gene (c.988A > G p.Lys330Glu), and two other patients without a known mutation (U-HAE) but with a family history of angioedema. The mean age at onset was $13.5 \pm 8.1$ years, with a mean time between first symptoms and diagnosis of $19.4 \pm 14.3$ years.

\section{Clinical Characteristics of the Patients}

The median age was 62 years (range 46 to 86 years). Seventytwo percent of the patients $(n=47)$ had at least one severe HAE episode during their lifetime. Overall, 69.2\% $(n=45)$ reported at least one episode of laryngeal edema, and four required intubation or tracheotomy. Severe abdominal attacks resulted in unnecessary laparotomy in $23 \%$ of the patients $(n=15)$. Forty-two percent $(n=27)$ of the patients had at least one disease concomitant to HAE. The clinical characteristics of HAE after menopause according to HAE type are described in Table 1.

\section{Influence of Hormonal Factors}

Seventy-one percent of the patients $(n=46)$ experienced their first symptoms or a worsening of attacks in the context of hormonal (estrogen-dependent) factors, including puberty, estroprogestin combined contraception (COC), perimenstrual period, and/or pregnancy (Table 2). Of the 43 patients who had used a COC, with an average duration of $7.7 \pm 8$ years, almost $56 \%(n=24)$ had worsening symptoms. Nineteen women used progestins during their lifetime: seven used low-dose progestin-only pills (POP) with one reporting improvement on treatment; 12 used stronger antigonadotropic agents (AGP) (chlormadinone acetate, nomegestrol acetate, norgestrienone at high doses), and eight of these reported an improvement in frequency of attacks under treatment.

\section{Menopause Characteristics}

The mean age at menopause was $50.2( \pm 4)$ years, and the mean duration between menopause and inclusion was 12.5 $( \pm 9.1)$ years. For $91 \%$ of the patients $(n=59)$, the diagnosis of menopause was clinical. Menopause was iatrogenic in $9.2 \%(n=6)$.

Menopausal symptoms were severe for almost half of the patients $(n=33)$. Hot flushes were high to very high for $26.1 \%$ $(n=17), 46.2 \%(n=30)$ reported physical and mental fatigue, and $46.2 \%(n=30)$ joint pain. Sleep problems were the most disabling, rated high to very high by $58.5 \%$ of the patients $(n=38)$. Vaginal dryness was high or very high for $32.3 \%$ $(n=21)$.

Table 2 Influence of hormonal factors on attack frequency according to subtype of HAE

\begin{tabular}{|c|c|c|c|c|c|}
\hline & $\begin{array}{l}\text { HAE type I } \\
(n=57)\end{array}$ & $\begin{array}{l}\mathrm{F} 12 \\
(n=5)\end{array}$ & $\begin{array}{l}\text { PLG } \\
(n=1)\end{array}$ & $\begin{array}{l}\text { U-HAE } \\
(n=2)\end{array}$ & $\begin{array}{l}\text { Total } \\
n(\%)\end{array}$ \\
\hline Worsening attack frequency (total), $n / N(\%)$ & $42 / 57(73.7)$ & $3 / 5(60.0)$ & 0 & $1 / 2(50.0)$ & $46(70.8)$ \\
\hline Puberty, $n / N(\%)$ & $23 / 57(40.4)$ & $1 / 5(20.0)$ & 0 & $1 / 2(50)$ & $25(38.5)$ \\
\hline Pregnancy, $n / N(\%)$ & $19 / 49(38.8)$ & $3 / 5(60.0)$ & 0 & $0 / 2(0)$ & $22(33.8)$ \\
\hline $\mathrm{COC}, n / N(\%)$ & $21 / 35(60.0)$ & $2 / 5(40.0)$ & 0 & $1 / 2(50.0)$ & $24(37.0)$ \\
\hline Menstrual cycle, $n / N(\%)$ & $18 / 57(31.6)$ & $1 / 5(20.0)$ & 0 & $1 / 2(50)$ & $20(30.7)$ \\
\hline MHT, $n / N(\%)$ & $3 / 11(27.3)$ & $0 / 2(0)$ & 0 & $0(0)$ & $3(27.3)$ \\
\hline Improving attack frequency (total), $n / N(\%)$ & $26 / 52(50.0)$ & $1 / 5(20.0)$ & na & $1 / 2(50.0)$ & $28 * *(43.0)$ \\
\hline Pregnancy, $n / N(\%)$ & $19 / 49(38.8)$ & $1 / 5(20.0)$ & 0 & $1 / 2(50)$ & $21(31.0)$ \\
\hline Progestins*, $n / N(\%)$ & $8 / 16(50.0)$ & $0 / 50.0)$ & 0 & na & $9(47.4)$ \\
\hline No effect, $n / N(\%)$ & $7 / 57(12.3)$ & $2 / 5(40.0)$ & 1 & $0 / 2(0.0)$ & $10(13.4)$ \\
\hline
\end{tabular}

COC combined hormonal contraception, MHT menopause hormone treatment, HAE type I hereditary angioedema with C1-Inhibitor deficiency, F12 nC1-INH-HAE with F12 mutation, PLG nC1-INH with plasminogen mutation, U-HAE HAE without known mutation

*Progestins: 1 of the 7 patients using low-dose progestin improved; 8 of the 12 patients using antigonadotropic progestins improved

**Some women improved with pregnancy and progestins 
Thirteen patients used MHT, with a mean duration of use of $8.6( \pm 7.6)$ years: transdermal $17 \beta$-estradiol (TTS-E2) (combined with a progestin) was used in $77 \%(n=10)$ and the oral route in $23 \%(n=3)$. Despite all belonged to the estrogen-sensitive group, interestingly only three of them experienced a worsening of attacks with MHT: two with TTS-E2 and one with the oral route. They all belonged to the HAE type I group. The progestin used is not specified due to memory bias.

\section{Postmenopausal Period and Severity of HAE}

Postmenopause was associated with an improvement in HAE symptoms in $38.5 \%$ of the patients $(n=25)$. There was no change in $46.1 \%$ patients $(n=30)$, and $15.4 \%$ patients $(n=$ 10) worsened (Tables 3 and 4).

More patients who were estrogen-sensitive during their childbearing years experienced an improvement after menopause. This difference tended towards significance in univariate analysis (0.06) and remained so in multivariate analysis (Table 3). Concerning long-term prophylactic treatment, 25 patients did not take any treatment after the menopause, 26 women were on danazol before menopause and 24 after ( 9 of the 26 stopped and 7 started), nine were using TA before menopause and 10 after, and none were taking a $\mathrm{C} 1-\mathrm{INH}$ derivative before compared to six after. There was no correlation between the severity of the climacteric symptoms and the course of HAE or with BMI, comorbidities, and the course of HAE after menopause (Table 3).

\section{Discussion}

This descriptive study provides some answers to the frequently asked questions about the course of HAE in women after menopause. Menopause resulted in an improvement in HAE for at least a third of the patients included, had no effect for about half (46\%), and caused worsening in 15\%. Our results contrast somewhat with the retrospective European study PREHAEAT including women with C1-INH-HAE: $55 \%$ reported no change in attacks after menopause, $32 \%$ worsened, and $13 \%$ improved [13]. However, this study included fewer patients $(n=44)$, no women with nC1-INH-HAE, and failed to specify a primary endpoint making comparison difficult. About two thirds of our patients experienced onset or worsening of attacks because of hormonal (estrogen-dependent) factors during their childbearing years and around $46 \%$ of these improved after menopause. We were surprised to see that there was no difference of the effect of menopause in women with $\mathrm{nC} 1-\mathrm{INH}-\mathrm{HAE}$ and those with $\mathrm{C} 1-\mathrm{INH}-\mathrm{HAE}$ but this may be because of the rather low number of patients with nC1-INH-HAE in our study. The patient with a mutation in the $P L G$ gene did not present any estrogen sensitivity. All the patients in our series with C1-INH-HAE had HAE type I which is in accordance with a previous French study where HAE type II represented only $6.7 \%$ of the patients and not the $15 \%$ usually reported $[2,19]$. The drop in estrogen levels at menopause may explain why some of these patients had fewer attacks [20]. Residual estrogen impregnation after menopause may vary from one woman to another, depending mainly on
Table 3 Course after menopause according to subtype of HAE and clinical characteristics (multivariate analysis)

\begin{tabular}{|c|c|c|c|c|}
\hline & $\begin{array}{l}\text { Improvement } \\
(n=25)\end{array}$ & $\begin{array}{l}\text { No effect } \\
(n=30)\end{array}$ & $\begin{array}{l}\text { Worsening } \\
(n=10)\end{array}$ & $P^{*}$ \\
\hline Age $($ mean \pm SD) & $62.5 \pm 10.0$ & $62.1 \pm 9.4$ & $64.9 \pm 6.5$ & NS \\
\hline Time since menopause & $12.2 \pm 8.3$ & $12.3 \pm 10.1$ & $13.7 \pm 7.2$ & NS \\
\hline \multicolumn{5}{|l|}{ Subtype of HAE, $n(\%)$} \\
\hline HAE type I & $22(88)$ & $26(86.6)$ & $9(90)$ & NS \\
\hline \multicolumn{5}{|l|}{ nC1-INH-HAE } \\
\hline F12 mutation & $2(8)$ & $2(6.7)$ & $1(10)$ & \multirow[t]{3}{*}{ NS } \\
\hline PLG mutation & 0 & $1(3.3)$ & 0 & \\
\hline U-HAE & $1(4)$ & $1(3.3)$ & $0(0)$ & \\
\hline \multicolumn{5}{|l|}{ Estrogen sensitivity, $n(\%)$} \\
\hline Estrogen worsening attack frequency & $21(84)$ & $17(56.7)$ & $8(80)$ & 0.06 \\
\hline \multicolumn{5}{|l|}{ Menopause severity, $n(\%)$} \\
\hline Severe & $14(56)$ & $14(47.7)$ & $4(40)$ & 0.39 \\
\hline BMI: obesity or overweight & $9(36)$ & $12(40)$ & $5(50)$ & NS \\
\hline Comorbidity, $n(\%)$ & $13(52)$ & $14(46.7)$ & $2(20)$ & NS \\
\hline
\end{tabular}

* $P$ was calculated for improvement compared with no effect or worsening

HAE Type I hereditary angioedema with $\mathrm{C} 1$ inhibitor deficiency, $F 12 \mathrm{nC} 1-\mathrm{INH}-\mathrm{HAE}$ with mutation factor XII, $P L G$ mutation nC1-INH-HAE with plasminogen mutation, U-HAE HAE without known mutation, BMI body mass index 
Table 4 Severity of disease in patients before and after menopause according to the score

\begin{tabular}{|c|c|c|c|c|c|}
\hline \multicolumn{2}{|l|}{ Improvement } & \multicolumn{2}{|l|}{ Worsening } & \multicolumn{2}{|l|}{ Stable } \\
\hline $\begin{array}{l}\text { Group (before and after } \\
\text { menopause) }\end{array}$ & $N$ & $\begin{array}{l}\text { Group (before and after } \\
\text { menopause) }\end{array}$ & $N$ & $\begin{array}{l}\text { Group (before and after } \\
\text { menopause) }\end{array}$ & $N$ \\
\hline 3 to 2 & 12 & 2 to 3 & 5 & 3 & 7 \\
\hline 3 to 1 & 4 & Total & 5 & 2 & 20 \\
\hline 3 to 0 & 1 & 1 to 2 & 1 & 1 & 3 \\
\hline Total & 17 & 1 to 3 & 1 & 0 & 4 \\
\hline 2 to 1 & 4 & Total & 2 & Total & 34 \\
\hline 2 to 0 & 4 & 0 to 1 & 1 & & \\
\hline total & 8 & 0 to 2 & 0 & & \\
\hline 1 to 0 & 0 & 0 to 3 & 2 & & \\
\hline Total & 0 & Total & 3 & & \\
\hline Total & 25 & Total & 10 & & \\
\hline
\end{tabular}

Group 3 severe, Group 2 moderate, Group 1 mild, Group 0 no attacks the degree of adiposity and the ability to aromatize androgens by the fatty tissue [21]. The climacteric syndrome is secondary to hypoestrogenism. Yet, we did not find a link between the intensity of the climacteric syndrome and a change in attacks after menopause.

Interestingly, only three of the 13 patients receiving MHT in our study had to stop treatment because of worsening of attacks. These results are surprising as estrogens activate factor 12, pre-kallikrein, and fibrinolytic proteins (PLG activator and PLG) [12, 14, 22-24]. Some studies have shown that MHT affects the kinin system resulting in a decrease in angiotensin-converting enzyme activity and an increase in bradykinin levels [25-27]. These observations suggest an increased risk of HAE attacks under MHT, and this is supported by the few cases reported in the literature which all describe a worsening of attacks under MHT [20, 28]. Two main hypotheses could explain our result. The first is that the levels of circulating estrogens under MHT are much lower than those observed when taking a COC or during pregnancy. Secondly, the transdermal route (used by around $80 \%$ of the women under MHT in our study) has a lower impact on the liver than the oral route and may be insufficient to induce worsening of attacks. This concurs with a previous study we conducted reporting that tamoxifen [29], a mild estrogen agonist but strongly impacting some proteins such as coagulation factors, is associated with a worsening of attacks through its effect on the liver. Two previous publications support this premise in reporting that plasma bradykinin levels are decreased by TTSE2 in healthy postmenopausal women and increased by oral conjugated estrogens (CEE); TTS-E2 has no effect on ACE activity whereas CEE significantly decreased ACE activity $[30,31]$. However, we would need a prospective trial to further confirm this hypothesis. If the result shows that at least some women tolerate MHT, it will help those women during the symptomatic phase of menopause. Indeed, the present study highlights the need to improve clinical management of the menopause in women with HAE. Twenty-six percent $(n=$ 17) of our patients reported disabling hot flushes, and none of them had a medical treatment for this symptom. Progesterone can be used safely in women with HAE and has been found to be effective on vasomotor symptoms and sleep disorders in randomized trials [32]. Progestin is also an interesting option and especially tibolone [33], a progestin partly metabolized into an androgen (delta4 isomer) [34]. A third of our patients also reported vaginal dryness, and none of them used topical estrogens despite a significant impact on their sexual life [35]. Although there is no specific data on vaginal estrogens in women with HAE, circulating levels of estradiol associated with twice-weekly administration is extremely low $(<20 \mathrm{pg} / \mathrm{ml})$ $[35,36]$ and, in our clinical experience, does not worsen attacks.

In addition to hormonal changes, aging is associated with comorbidities which could increase the frequency of HAE attacks [37]. The effects of aging on the kinin cascade, for example, may affect the course of the disease. Several studies have found that concentrations of high molecular weight kininogen and prekallikrein increase with age in healthy humans $[38,39]$. An in vitro rat study also showed an age-related elevation of high molecular weight kininogen serum levels and circulating kinin, associated with a concomitant decrease in endothelial cell kinase reactivity $[40,41]$. The significant decrease in B2 receptor expression by age-related coronary artery endothelial cells, found in mice and rats [42, 43], may explain this decrease in endothelial cell responsiveness to kinin, despite increased serum levels. Nevertheless, in humans, aging is associated with a chronic inflammatory status with an increase in pro-inflammatory cytokines [44]. Menopause is also associated with an increased adiposity, particularly abdominal adiposity, and insulin resistance. These are major determinants of the metabolic syndrome [45, 46], which is 
positively associated with the pro-inflammatory state [47], and thus, a conserved or even increased reactivity to kinin depending on the pro-inflammatory status of patients. This hypothesis would explain the observed variability in the course of HAE at menopause. It could also explain the worsening observed in two patients aged over 80 years in our study after 30 years of absence of attacks [48]. It would have been useful to assay pro- and anti-inflammatory cytokines in our sample to assess the inflammatory status of the patients and confirm this hypothesis.

The main limitation of our study is due to its retrospective design. We tried to overcome this limitation by using the HAE severity score as a measurement of HAE progression after menopause. This score takes into account the frequency of attacks over the last 6 months, the occurrence of lifethreatening angioedema episodes, and long-term prophylactic treatment. However, it could underestimate the impact of menopause on the frequency of attacks in patients who already had long-term prophylactic treatment in the premenopausal period. This may result in an overestimation of patients with no menopausal effect at the expense of patients improving at menopause. Another limitation is that memory bias may have impacted our results, mainly for the 5 premenopausal years. A prospective study conducted during the transition to menopause period would be an interesting next step to better understand the changes brought about by menopause.

\section{Conclusion}

Menopause has mixed effects on HAE progression. Improvement was mainly observed in patients with a previous estrogen sensitivity while most patients were stable and a few worsened. This study highlights that management of menopause in women with HAE is suboptimal and should encourage clinicians to improve the quality of life for these patients. As proposed, progesterone and progestins can be used with benefit in these women for their climacteric symptoms and possibly transdermal estradiol if confirmed in a study.

Acknowledgements Centre de Référence sur les angiœedèmes à kinines [CRéAk] includes S. Amarger, MD (CHU Estaing, Clermont Ferrand, France), C. Blanchard-Delaunay, MD (CH Niort, France), B. Coppere, MD (Hospices Civils de Lyon, CHU Edouard Herriot, Lyon, France), A. DuThanh, MD (CHU Montpellier, France), B. Floccard, MD (Hospices Civils de Lyon, CHU Edouard Herriot, Lyon, France), S. Gayet, MD (Hospital La Timone, APHM, Marseille, France), P. Y. Jeandel, MD (CHU Nice, France), L. Martin, MD PhD (CHU Angers, France), F. Pelletier, MD (CRHU Besançon, France), F. N. Raison Peyron, MD (Hospital St Eloi, Montpellier, France). Thanks to Felicity Neilson for editing the manuscript in English.

Funding This research did not receive any specific grant from funding agencies in the public, commercial, or not-for-profit sectors.

\section{Compliance with Ethical Standards}

Conflict of Interest AB: no conflict of interest, OF: Consultant arrangements for Shire/Takeda and Behring, travel and accommodation to a Congress from GSK, honorarium for a talk from Sanofi, DL: consultant arrangements, research grant and travel and accommodation from Actelion, GSK, Octapharma, Pfizer, and Shire/Takeda. LB: Consultant arrangements, research grant and travel and accommodation from Shire/ Takeda, CSL Behring, Pharming, GSK, Novartis, Sanofi. I B-G: Consultant arrangements, research grant, travel and accommodation from Shire/Takeda, CSL Behring, Pharming, Biocryst, Novartis DG: Consultant arrangements for Shire/Takeda honorarium for talks for Shire/Takeda, travel and accommodation from Shire/Takeda et Pharming. G.P-B: no conflict of interest. AG: member of an advisory board for Mithra (Estetrol).

\section{References}

1. Cicardi M, Aberer W, Banerji A, Bas M, Bernstein JA, Bork K, et al. Classification, diagnosis, and approach to treatment for angioedema: consensus report from the Hereditary Angioedema International Working Group. Allergy. 2014;69:602-16.

2. Betschel S, Badiou J, Binkley K, Borici-Mazi R, Hébert J, Kanani $\mathrm{A}$, et al. The International/Canadian Hereditary Angioedema Guideline. Allergy Asthma Clin Immunol Off J Can Soc Allergy Clin Immunol [Internet]. 2019 [cited 2020 Mar 30];15. Available from: https:/www.ncbi.nlm.nih.gov/pmc/articles/PMC6878678/.

3. Wu MA, Perego F, Zanichelli A, Cicardi M. Angioedema phenotypes: disease expression and classification. Clin Rev Allergy Immunol. 2016;51:162-9.

4. Zuraw BL, Bork K, Binkley KE, Banerji A, Christiansen SC, Castaldo A, et al. Hereditary angioedema with normal $\mathrm{C} 1$ inhibitor function: consensus of an international expert panel. Allergy Asthma Proc. 2012;33(Suppl 1):S145-56.

5. Bova MC, Bafunno V, et al. Impaired control of the contact system in hereditary angioedema with normal $\mathrm{C} 1$-inhibitor allergy. Allergy. 2020 Jun;75(6):1394-1403. https://doi.org/10.1111/all. 14160

6. Lopes Veronez C, Sevciovic Grumach A. Angioedema without urticaria: novel findings which must be measured in clinical setting. Curr Opin Allergy Clin Immunol. 2020 Jun;20(3):253-60.

7. Banday AZ, Jindal AK, EAwat A, Singh S. An update on the genetics and pathogenesis of hereditary angioedema. Genes Dis. 2019;7(1):75-83.

8. Bork K, Wulff K, Steinmüller-Magin L, et al. Hereditary angioedema with a mutation in the plasminogen gene. Allergy. 2017;00:1e9.

9. Bafunno V, Firinu D, D'Apolito M, et al. Mutation of the angiopoietin-1 gene (ANGPT1) associates with a new type of hereditary angioedema. J Allergy Clin Immunol. 2018;141: $1009 \mathrm{e} 1117$

10. Bork K, Wulff K, Rossmann H, Steinmüller-Magin L, Braenne I, Witzke G, et al. Hereditary angioedema cosegregating with a novel kininogen 1 gene mutation changing the $\mathrm{N}$-terminal cleavage site of bradykinin. Allergy. 2019;74:2479-81.

11. Caballero T, Farkas H, Bouillet L, et al. International consensus and practical guidelines on the gynecologic and obstetric management of female patients with hereditary angioedema caused by $\mathrm{C} 1$ inhibitor deficiency. J Allergy Clin Immunol. 2012;129:308-20.

12. Bouillet L, Longhurst H, Boccon-Gibod I, Bork K, Bucher C, Bygum A, et al. Disease expression in women with hereditary angioedema. Am J Obstet Gynecol. 2008;199:484.e1-4. 
13. Gompel A, Fain O, Boccon-Gibod I, Gobert D, Bouillet L. Exogenous hormones and hereditary angioedema. Int Immunopharmacol. 2020;78:106080.

14. Zotter Z, Csuka D, Szabó E, Czaller I, Nébenführer Z, Temesszentandrási $\mathrm{G}$, et al. The influence of trigger factors on hereditary angioedema due to $\mathrm{C} 1$-inhibitor deficiency. Orphanet J Rare Dis. 2014;9:44.

15. Gelfand JA, Sherins RJ, Alling DW, Frank MM. Treatment of hereditary angioedema with danazol. Reversal of clinical and biochemical abnormalities. N Engl J Med. 1976;295:1444-8.

16. Heinemann LAJ, DoMinh T, Strelow F, Gerbsch S, Schnitker J, Schneider HPG. The Menopause Rating Scale (MRS) as outcome measure for hormone treatment? A validation study. Health Qual Life Outcomes. 2004;2:67.

17. MRS - Menopause Rating Scale [Internet]. [cited 2020 Apr 25]. Available from: http://www.menopause-rating-scale.info/.

18. Prior N, Remor E, Pérez-Fernández E, Caminoa M, GómezTraseira C, Gayá F, et al. Psychometric field study of hereditary angioedema quality of life questionnaire for adults: HAE-QoL. J Allergy Clin Immunol Pract. 2016;4:464 473.e4.

19. Bouillet L, Launay D, Fain O, Boccon-Gibod I, Laurent J, Martin L, et al. Hereditary angioedema with $\mathrm{C} 1$ inhibitor deficiency: clinical presentation and quality of life of 193 French patient. Ann Allergy Asthma Immunol. 2013;111(4):290-4.

20. Visy B, Füst G, Varga L, Szendei G, Takács E, Karádi I, et al. Sex hormones in hereditary angioneurotic oedema. Clin Endocrinol. 2004;60:508-15.

21. Poortman J, Thijssen JH, de Waard F. Plasma oestrone, oestradiol and androstenedione levels in post-menopausal women: relation to body weight and height. Maturitas. 1981;3:65-71.

22. Luyer MD, Khosla S, Owen WG, Miller VM. Prospective randomized study of effects of unopposed estrogen replacement therapy on markers of coagulation and inflammation in postmenopausal women. J Clin Endocrinol Metab. 2001;86:3629-34.

23. Madsen JS, Kristensen SR, Gram J, Bladbjerg EM, Henriksen FL, Gram J, et al. Positive impact of hormone replacement therapy on the fibrinolytic system: a long-term randomized controlled study in healthy postmenopausal women. J Thromb Haemost JTH. 2003;1: 1984-91.

24. Thiery M, Vermeulen A, Baele G, Deslypere JP. Effects of a very low-estrogen oral contraceptive on clotting factors, carbohydrate metabolism and plasma lipids and lipoproteins. Med Sci Res. 1987;15:1231-2.

25. Gallagher PE, Li P, Lenhart JR, Chappell MC, Brosnihan KB. Estrogen regulation of angiotensin-converting enzyme mRNA. Hypertens Dallas Tex 1979. 1999;33:323-8.

26. Nogawa N, Sumino H, Ichikawa S, Kumakura H, Takayama Y, Nakamura T, et al. Effect of long-term hormone replacement therapy on angiotensin-converting enzyme activity and bradykinin in postmenopausal women with essential hypertension and normotensive postmenopausal women. Menopause N Y N. 2001;8:210-5.

27. Sumino H, Ichikawa S, Ohyama Y, Nakamura T, Kanda T, Sakamoto H, et al. Effects of hormone replacement therapy on serum angiotensin-converting enzyme activity and plasma bradykinin in postmenopausal women according to angiotensinconverting enzyme-genotype. Hypertens Res Off J Jpn Soc Hypertens. 2003;26:53-8.

28. McGlinchey PG, McCluskey DR. Hereditary angioedema precipitated by estrogen replacement therapy in a menopausal woman. Am J Med Sci. 2000;320:212-3.

29. Rousset-Jablonski C, Thalabard J-C, Gompel A. Tamoxifen contraindicated in women with hereditary angioedema? Ann Oncol Off J Eur Soc Med Oncol. 2009;20:1281-2.
30. Ichikawa J, Sumino H, Ichikawa S, Ozaki M. Different effects of transdermal and oral hormone replacement therapy on the reninangiotensin system, plasma bradykinin level, and blood pressure of normotensive postmenopausal women. Am J Hypertens. 2006;19:744-9.

31. Ichikawa A, Sumino H, Ogawa T, Ichikawa S, Nitta K. Effects of long-term transdermal hormone replacement therapy on the reninangiotensin- aldosterone system, plasma bradykinin levels and blood pressure in normotensive postmenopausal women. Geriatr Gerontol Int. 2008;8:259-64.

32. Hitchcock CL, Prior JC. Oral micronized progesterone for vasomotor symptoms-a placebo-controlled randomized trial in healthy postmenopausal women. Menopause N Y N. 2012;19:886-93.

33. Ott HW, Mattle V, Hadziomerovic D, Licht P, Döinghaus K, Rubbert A, et al. Treatment of hereditary angioneurotic oedema (HANE) with tibolone. Clin Endocrinol. 2007;66:180-4.

34. Kloosterboer HJ. Tibolone: a steroid with a tissue-specific mode of action. J Steroid Biochem Mol Biol. 2001;76:231-8.

35. Stuenkel CA, Davis SR, Gompel A, Lumsden MA, Murad MH, Pinkerton JV, et al. Treatment of symptoms of the menopause: an endocrine society clinical practice guideline. J Clin Endocrinol Metab. 2015;100:3975-4011.

36. Del Pup L, Postruznik D, Corona G. Effect of one-month treatment with vaginal promestriene on serum estrone sulfate levels in cancer patients: a pilot study. Maturitas. 2012;72:93-4.

37. Salive ME. Multimorbidity in older adults. Epidemiol Rev. 2013;35:75-83.

38. Hager K, Setzer J, Vogl T, Voit J, Platt D. Blood coagulation factors in the elderly. Arch Gerontol Geriatr. 1989;9:277-82.

39. Pérez V, Velarde V, Acuña-Castillo C, Gómez C, Nishimura S, Sabaj $\mathrm{V}$, et al. Increased kinin levels and decreased responsiveness to kinins during aging. J Gerontol A Biol Sci Med Sci. 2005;60: 984-90.

40. Sierra F. Both T- and K-kininogens increase in the serum of old rats but by different mechanisms. Mech Ageing Dev. 1995;84:127-37.

41. Feng W, Xu X, Zhao G, Zhao J, Dong R, Ma B, et al. Increased agerelated cardiac dysfunction in Bradykinin $\mathrm{B} 2$ receptor-deficient mice. J Gerontol A Biol Sci Med Sci. 2016;71:178-87.

42. Kintsurashvili E, Duka A, Ignjacev I, Pattakos G, Gavras I, Gavras H. Age-related changes of bradykinin $\mathrm{B} 1$ and $\mathrm{B} 2$ receptors in rat heart. Am J Physiol Heart Circ Physiol. 2005;289:H202-5.

43. Nurmi L, Heikkilä HM, Vapaatalo H, Kovanen PT, Lindstedt KA. Downregulation of Bradykinin type 2 receptor expression in cardiac endothelial cells during senescence. J Vasc Res. 2012;49:13-23.

44. Montgomery RR, Shaw AC. Paradoxical changes in innate immunity in aging: recent progress and new directions. J Leukoc Biol. 2015;98(6):937-43.

45. Carr MC. The emergence of the metabolic syndrome with menopause. J Clin Endocrinol Metab. 2003;88:2404-11.

46. Moreau KL, Stauffer BL, Kohrt WM, Seals DR. Essential role of estrogen for improvements in vascular endothelial function with endurance exercise in postmenopausal women. J Clin Endocrinol Metab. 2013;98:4507-15.

47. Rosen ED, Spiegelman BM. Adipocytes as regulators of energy balance and glucose homeostasis. Nature. 2006;444:847-53.

48. Kleniewski J, Czokało M. Plasma kininogen concentration: the low level in cord blood plasma and age dependence in adults. Eur J Haematol. 1991;46:257-62.

Publisher's Note Springer Nature remains neutral with regard to jurisdictional claims in published maps and institutional affiliations. 